\title{
Effect of SBF on Cyclic Compression Behaviour of Porous Titanium Component for Implant Application
}

\author{
Munshi Muhammad Raihan", Afrina Khan Piya ${ }^{1}$, Mohammad Alamgir Hossain ${ }^{2, *}$ \\ ${ }^{1}$ Department of Mechanical Engineering, Nagaoka University of technology, Nagaoka City, Niigata, Japan \\ ${ }^{2}$ Department of Mechanical Engineering, Military Institute of Science and Technology, Dhaka, Bangladesh
}

Email address:

raihan.mist@gmail.com (M. M. Raihan), afrina.mist@gmail.com (A. K. Piya), ahossain@me.mist.ac.bd (M. A. Hossain)

${ }^{*}$ Corresponding author

\section{To cite this article:}

Munshi Muhammad Raihan, Afrina Khan Piya, Mohammad Alamgir Hossain. Effect of SBF on Cyclic Compression Behaviour of Porous Titanium Component for Implant Application. Industrial Engineering. Vol. 4, No. 2, 2020, pp. 50-54. doi: 10.11648/j.ie.20200402.14

Received: June 25, 2020; Accepted: August 24, 2020; Published: September 3, 2020

\begin{abstract}
In the recent years, porous structure is being drawn attention to the researcher for implant application for superior characteristics over bulk materials. The aim of this study is to evaluate the cyclic compression behaviour of porous titanium components in simulated body fluid (SBF). Porous titanium component developed by replica impregnation method was taken for study. Compression tests in air revealed that the yield strength of the porous body is $8 \mathrm{MPa}$ on average and elastic modulus is around $180 \mathrm{MPa}$ which is compatible to cancellous bone application. After $10 \%$ strain porous structure deformed plastically producing a long plateau region. Compressive fatigue tests revealed that at higher stress level porous titanium failed earlier in SBF than in air. In contrast, fatigue limit of porous substrate is $2 \mathrm{MPa}$ which was not affected by SBF medium. After 10 million cycles in SBF, Calcium Phosphate layer was partially formed on the surface of porous titanium by re-precipitation from SBF. EDS analysis showed that the $\mathrm{Ca} / \mathrm{P}$ atomic ratio was 1.44 which is near to beta TCP and HA phase and these phases are beneficial for bone tissue ingrowth.
\end{abstract}

Keywords: SBF, Cyclic Compression Behaviour, Porous Titanium, Implant Application, Corrosion Resistance, EDS Analysis, Osteoconductivity, and Bioactive Coating

\section{Introduction}

Titanium and its alloy are being widely used for prosthetic implant material due its superior mechanical properties and corrosion resistance. Though their elastic modulus $(110 \mathrm{GPa})$ is lower than other metallic material but still much higher than human bone which generates stress shielding effect during gait which cause pain to the patients [1]. The stress shielding effect is responsible for implant loosening and revision surgery and also causes bone resorption. So porous structures of metallic material are being developed by different method such as replica impregnation, additive manufacturing, 3D printing, selective laser melting etc. [2]. The porous structures can be either open cell or close cell. The open cell porous structure not only helps for bone ingrowth but also provides space for fluid transformation which provides long term stability. Some researchers reported that the pore size ranging from 100 to $400 \mathrm{~mm}$ was effective for bone formation whereas pore size below this range limits the ingrowth of bone tissue, while pore size much higher than this range make no significant difference or even increase the possibility of fibrous tissue formation [3-6]. SEM and EDX analysis revealed cell morphology were identical for HAp and HAp/amino acid ligands complex coating [7]. Such characteristics are desirable for the success of implant biomaterial coating that can preserve both antibacterial property and cell adhesion behavior. Significant research works have been done to manufacture porous scaffold by different method and their mechanical behaviour as well as compression fatigue behaviour was evaluated for long term durability [8-13]. These studies were confined to air environment only and effect of SBF was studied only by static immersion without applying any load. However, very few literatures were found to evaluate the effect of body fluid on cyclic compression behaviour of developed implant material which may reduce the fatigue limit. Thus, our study focused on particularly the effect of simulated body fluid on 
cyclic compression behaviour of porous titanium scaffold developed by replica impregnation method. Surface morphology before and after fatigue test was evaluated using digital microscope, scanning electron microscope along with EDS analysis and mapping.

\section{Experimental Procedure}

\subsection{Specimen Preparation}

Commercial pure porous titanium bar was fabricated by replica impregnation method having $90 \%$ porosity similar to cancellous bone [7]. After that porous titanium specimen was prepared by wire cutting having $9 \mathrm{~mm}$ height and $9 \mathrm{~mm}$ dia. The chemical composition of porous titanium is presented on table 1 .

Table 1. Chemical compositions of commercially pure titanium (wt.\%) [7].

\begin{tabular}{ll}
\hline Chemical Compositions & Percentage of wt. \\
\hline $\mathrm{Fe}$ & 0.033 \\
$\mathrm{H}$ & 0.006 \\
$\mathrm{~N}$ & 0.009 \\
$\mathrm{C}$ & 0.005 \\
$\mathrm{O}$ & 0.113 \\
$\mathrm{Ti}$ & Balance \\
\hline
\end{tabular}

\subsection{Monotonic Compression Test}

Compression tests for porous Ti specimens were conducted using a servo hydraulic fatigue testing machine (load cell capacity; 30 kN, Shimadzu Co. Ltd., Japan). The crosshead speed was $-1 \mathrm{~mm} / \mathrm{min}$ and the maximum displacement was -5 $\mathrm{mm}$. Data was collected using PCD-300 series software system and recording frequency was $50 \mathrm{~Hz}$.

\subsection{Cyclic Compression Test in SBF}

Compressive fatigue tests in SBF were conducted for porous titanium using the same fatigue machine used for the compression tests. The tests were carried out by controlling the maximum compressive stress with a loading frequency of $10 \mathrm{~Hz}$ and stress ratio 10. Fatigue limit was defined by the number of cycles when cumulative compressive displacement of the porous specimen reached to $10 \%$. The applied maximum stress was equal to $0.75 \sigma_{y}, 0.5 \sigma_{y}, 0.25 \sigma_{y}$. Fatigue limit was calculated for 10 million cycle. For fatigue testing in simulated body fluid (SBF), a cylindrical SBF holder was assembled with fatigue testing machine. SBF was prepared according to the composition given by Tadashi Kokubo et. al. [14] presented in table 2 . The tests were carried out using the same conditions as those in air. The temperature of SBF medium was maintained at $37 \pm 1^{\circ} \mathrm{C}$ using a temperature controller (MTCS 15-BN) and $\mathrm{pH}$ was maimed at 7.4. The SBF medium was changed every three days to avoid depletion calcium phosphate ions in the solution.

Table 2. Amount of chemical for 1L SBF preparation [13].

\begin{tabular}{ll}
\hline Chemical & Amount (gm) \\
\hline $\mathrm{NaCl}$ & 8.035 \\
$\mathrm{NaHCO}_{3}$ & 0.355 \\
\hline
\end{tabular}

\begin{tabular}{ll}
\hline Chemical & Amount (gm) \\
\hline $\mathrm{KCl}$ & 0.225 \\
$\mathrm{~K}_{2} \mathrm{HPO}_{4} \cdot 3 \mathrm{H}_{2} \mathrm{O}$ & 0.231 \\
$\mathrm{MgCl}_{2} \cdot 6 \mathrm{H}_{2} \mathrm{O}$ & 0.311 \\
$\mathrm{CaCl}_{2}$ & 0.292 \\
$\mathrm{Na}_{2} \mathrm{SO}_{4}$ & 0.072 \\
$\mathrm{Tris}$ & 6.118 \\
$\mathrm{HCl}(\mathrm{mol} / \mathrm{L})$ & $39+5$ \\
\hline
\end{tabular}

\subsection{SEM Observation}

The surface morphology was observed using a microscope camera (VHX-1000). Scanning electron microscopy (SEM) (JSM-6306A, JEOL Ltd., Japan) was conducted. Elemental composition after SBF testing was also carried out by EDS analysis.

\section{Result and Discussion}

\subsection{Surface Morphology}

From digital microscope observation (figure 1 (a)) significant pores were detected on the surface of the porous titanium. SEM observation showed the wavy pattern of the surface and the pore size was measured $10-20 \mathrm{~mm}$ whereas average pore size was $300-600 \mathrm{~mm}$.

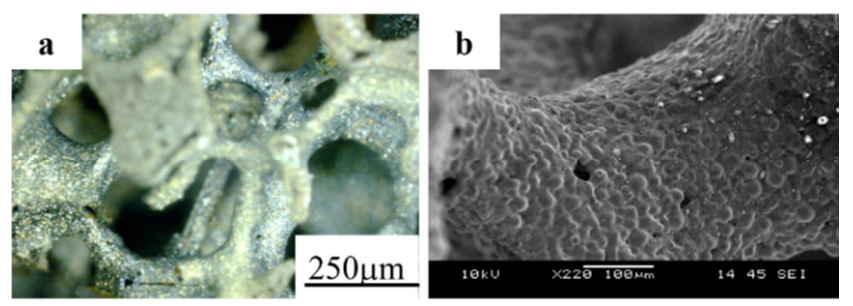

Figure 1. Surface morphology of porous pure titanium (a) Optical observation (b) SEM observation.

\subsection{Monotonic Compression Test}

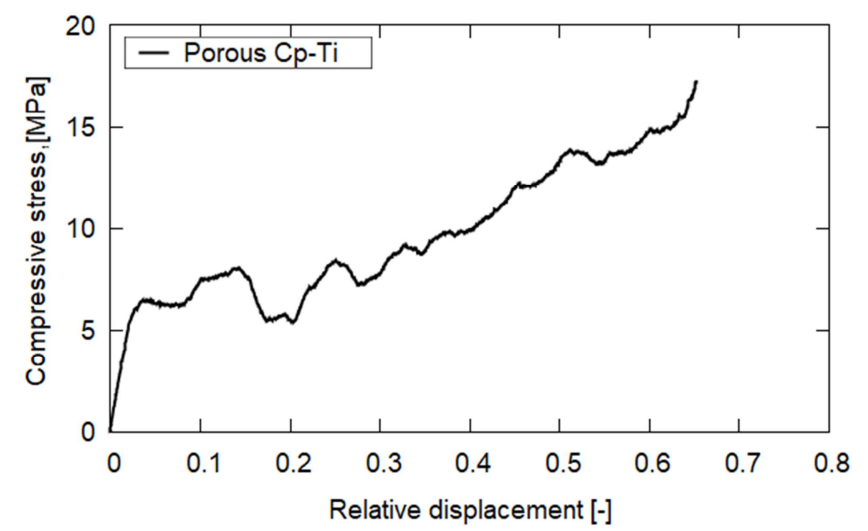

Figure 2. Compressive stress vs relative displacement curve.

From the compressive stress vs compressive relative displacement graph shown in figure 2 , it can be observed that $0.2 \%$ proof strength of porous titanium is around $8 \mathrm{MPa}$. Compressive elastic modulus of porous titanium was $180 \mathrm{MPa}$ which is identical to the one of cancellous bone (100-1000MPa) [15]. The long plateau region showed the load 
drop by strut breaking and again load rising due to support by other struts. After $10 \%$ increment of the strain, the porous body entered to the plastic region. This is why $10 \%$ strain was chosen as the breaking point during fatigue test.

\subsection{Effect of SBF on Cyclic Compression Loading}

The S-N curve (figure 3) showed that at higher stress level the porous titanium scaffold failed much earlier in SBF than ambient condition. The fatigue limit was found $2 \mathrm{MPa}$ which was not affected by Simulated Body Fluid. Figure 4 showed the progressive compressive strain of the porous component with increment of cycle. At initial stage (Stage I) compressive strain increased rapidly due to applied maximum stress. After reaching the saturation point, strain increased gradually (Stage II). When reaching at the critical point strain increased drastically at the final stage (Stage III) leading to final fracture of the porous body. Similar result was observed by other researchers also [11].

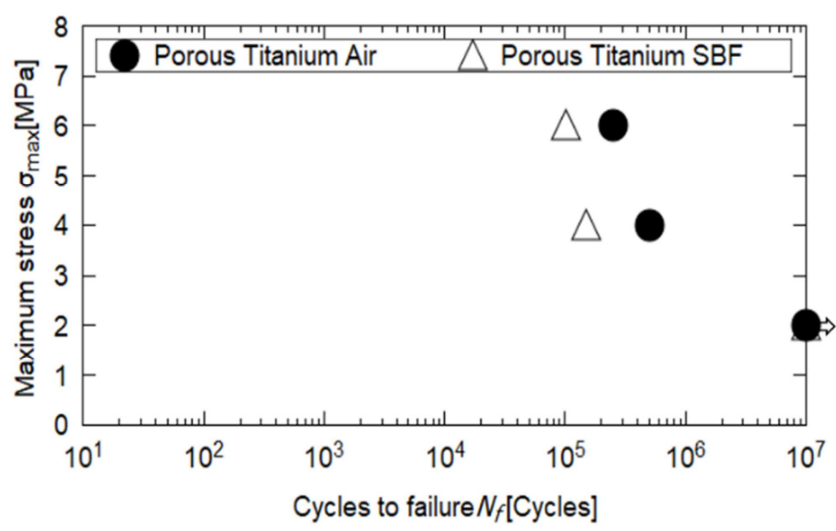

Figure 3. Compressive fatigue lives of porous titanium in air and in SBF.

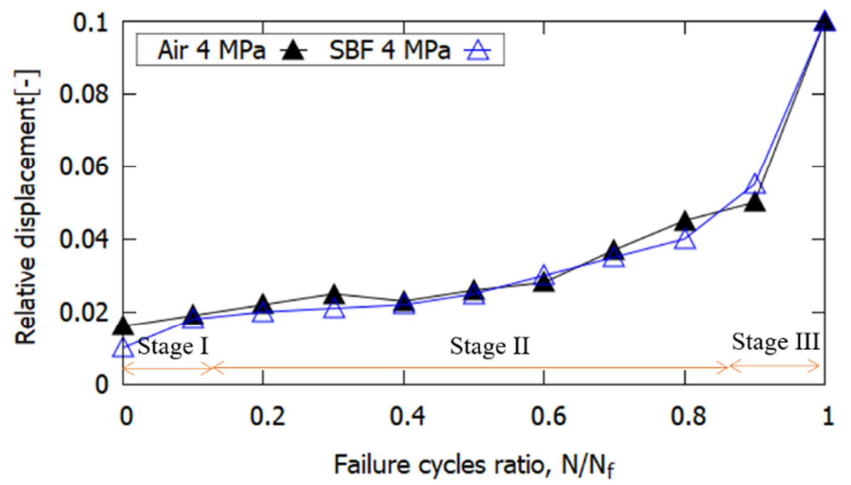

Figure 4. Accumulation of compressive relative displacement during fatigue tests in Air and SBF.

\subsection{SEM Observation of Fracture Surface After SBF Testing}

From fracture surface observation (figure 5) it was found that fracture generated from the pores remained in the porous titanium surface especially from the meshing point in struts which causes stress concentration during cyclic loading. From the figure 6 it is clear that calcium phosphate layer partially formed on the surface of porous titanium component even though under cyclic loading in Simulated Body Fluid. From EDS analysis in figure 7 and mapping in figure 8 , the presence of calcium phosphate was confirmed and calcium phosphate $(\mathrm{Ca} / \mathrm{P})$ atomic ratio was calculated 1.44, which is near to b-TCP and HA phase and these phases are highly recommended for osteoconductivity [16]. This result clearly proved the biocompatibility of porous titanium components developed by replica impregnation method.

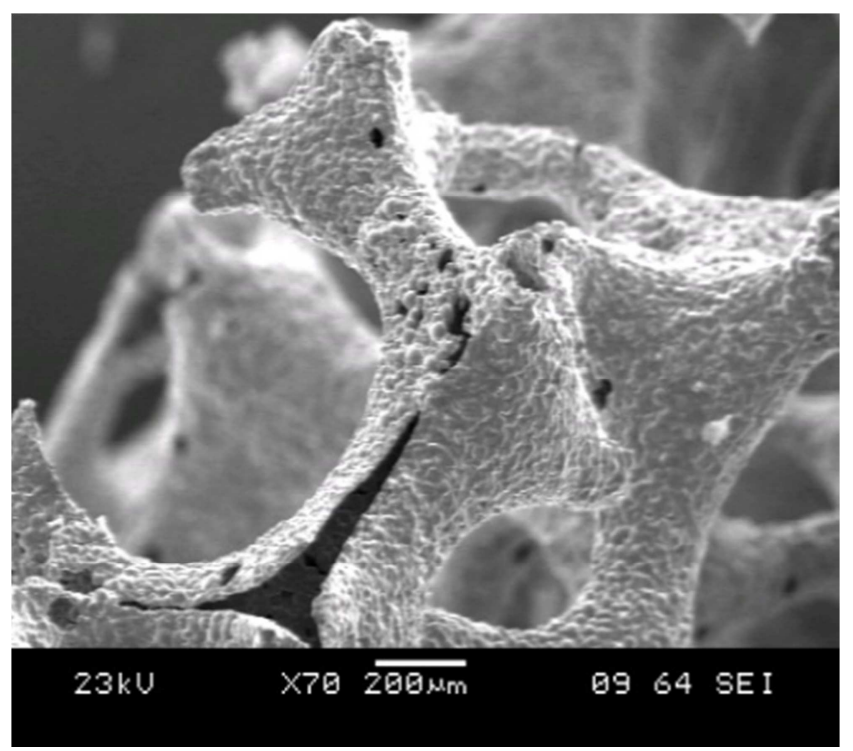

Figure 5. SEM observation of cracking from microspores leading to fracture of trunk.
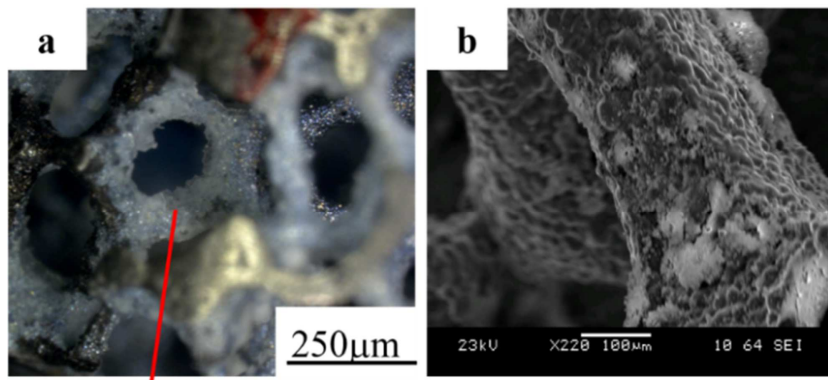

Precipitated layer

Figure 6. Optical image (a) and SEM image (b) of precipitated surface after fatigue test at $2 \mathrm{MPa}$ in $\mathrm{SBF}$. 


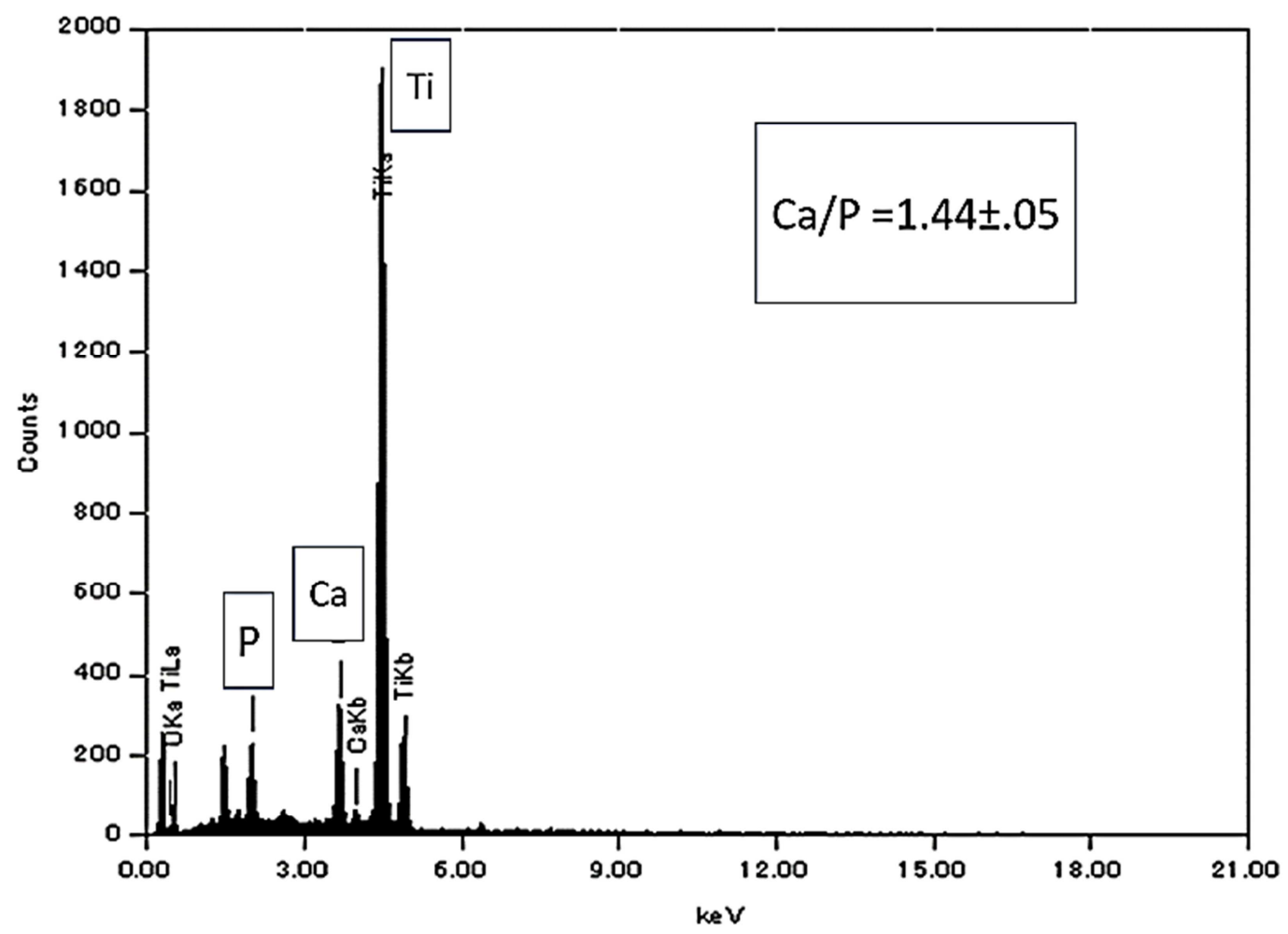

Figure 7. EDS analysis precipitated surface in the region of figure 6 (b).

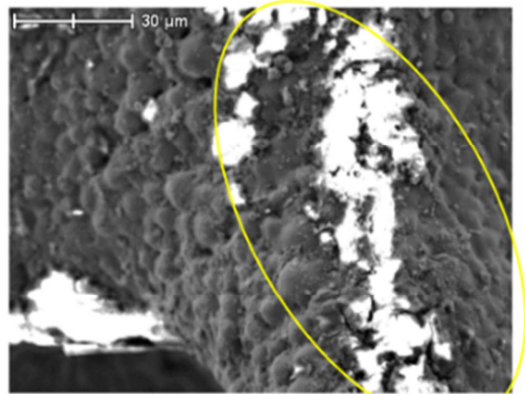

After 10million cycle

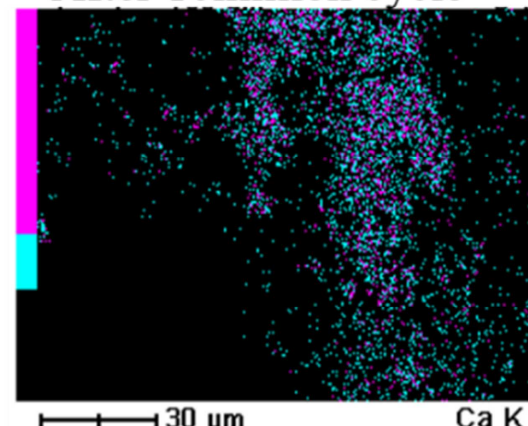

$\mathrm{CaK}$
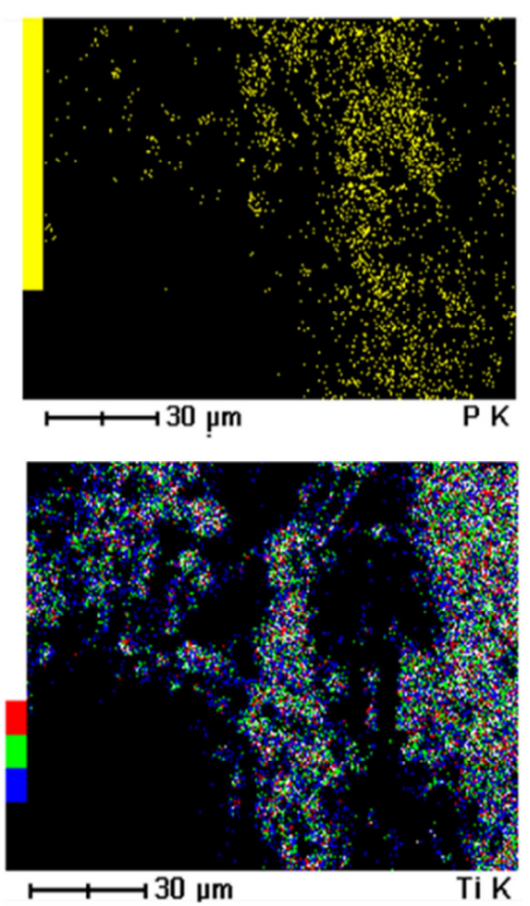

Figure 8. Mapping for Ca, $P$ content after cyclic loading testing at $2 \mathrm{MPa}$ in SBF.

\section{Conclusion}

Monotonic compression test revealed that yield stress of porous titanium developed by replica impregnation method is compatible with cancellous bone. Fatigue limit was found $2 \mathrm{MPa}$ which was not affected by SBF environment. Though the porous component in SBF was subjected to cyclic loading, calcium phosphate particles can be precipitate partially which indicates high biocompatibility. Finally, it can be concluded that porous titanium components studied here can be an excellent candid for implant application. Further modification of porous titanium surface by applying some bioactive coating can be more beneficial bone tissue adhesion and osseointegration. 


\section{Conflicts of Interest}

The authors declare that they have no competing interest.

\section{References}

[1] Tennison M, Caleb RS, Nicholas KS, Alison KK, Siran MK, Wael KB. (2015). Prevalence and Perioperative Outcomes of Off-Label Total Hip and Knee Arthroplasty in the United States, 2000-2010. The Journal of Arthroplasty, 30 (11): 1872-1878.

[2] Andy FZ, Paymon R, Kevin CC. (2018). Advances in Proximal Interphalangeal Joint Arthroplasty: Biomechanics and Biomaterials. Hand Clinics. 34 (2): 185-194.

[3] Karageorgiou V, Kaplan D. (2005). Porosity of 3D biomaterial scaffolds and osteogenesis. Biomaterials. 26 (27): 5474-5491.

[4] Hulbert SF, Young FA, Mathews RS, Klawitter JJ, Talbert CD, Stelling FH. (1970). Potential of ceramic materials as permanently implantable skeletal prostheses. J. Biomed. Mater. Res. 4 (3): 433-456.

[5] Bai F, Wang Z, Lu J, Liu J, Chen G, Lv R, Wang J, Lin K, Zhang J, Huang XGI. (2010). The correlation between the internal structure and vascularization of controllable porous bioceramic materials in vivo: a quantitative study. Tissue Eng. Part A. 16 (12): 3791-3803.

[6] Ryan G, Pandit A, Apatsidis DP. (2006). Fabrication methods of porous metals for use in orthopaedic applications. Biomaterials. 27: 2651-2670.

[7] Piya AK, Raihan MM, Hossain MA. (2020). Effect of Osteoblasts Cell Adhesion Behavior on Biomaterial Surfaces by Atomic Force Microscope. Advances in Applied Sciences. 5 (1): $1-10$.

[8] Manonukul A, Srikudvien P, Tange M. (2016). Microstructure and mechanical properties of commercially pure titanium foam with varied cell size fabricated by replica impregnation method. Materials Science and Engineering: A. 650: 432-437.

[9] Hedayati R, Janbaz S, Sadighi M, Mohammadi-Aghdam M, Zadpoor AA. (2017). How does tissue regeneration influence the mechanical behavior of additively manufactured porous biomaterials? Journal of the Mechanical Behavior of Biomedical Materials. 65: 831-841.

[10] Hedayati R, Yavari SA, Zadpoor AA. (2017). Fatigue crack propagation in additively manufactured porous biomaterials. Materials Science and Engineering: C. 76: 457-463.

[11] de Krijger J, Rans C, Van Hooreweder B, Lietaert K, Pouran B, Zadpoor AA. (2017). Effects of stress ratio on the fatigue behavior of additively manufactured porous biomaterials under compressive loading. Journal of Mechanical Behavior of Biomedical Materials. 70: 7-16.

[12] Li F, Li J, Huang T, Kou H, Zhou L. (2016). Compression fatigue behavior and failure mechanism of porous titanium for biomedical applications, Materials Science and Engineering: $C$. 60: 485-488.

[13] Özbilen S, Liebert D, Beck T, Bram M. (2016). Fatigue behavior of highly porous titanium produced by powder metallurgy with temporary space holders. Materials Science and Engineering: C. 60: 446-457.

[14] Kokubo T, Takadama H. (2006). How useful is SBF in predicting in Vivo bone bioactivity? Biomaterials. 27 (15): 2907-29.

[15] Robert BH. (2006). Thermal spraying of biomaterials. Surface and Coatings Technology. 201 (5): 2012-2019.

[16] Windarti T, Darmawan A, Marliana A. (2019). Synthesis of $\beta$-TCP by sol-gel method: variation of $\mathrm{Ca} / \mathrm{P}$ molar ratio. IOP Conf. Ser. Material Science Engineering. 509 (1): 012147. 